\title{
Physiologic, Anatomic, and Gene Expression Changes in Citrus sunki, Poncirus trifoliata, and Their Hybrids After 'Candidatus Liberibacter asiaticus' Infection
}

\author{
Leonardo Pires Boava, Mariângela Cristofani-Yaly, and Marcos Antonio Machado
}

First, second, and third authors: Centro de Citricultura Sylvio Moreira, CP4, 13490-970, Cordeirópolis-São Paulo-Brazil. Accepted for publication 3 January 2017.

\begin{abstract}
Huanglongbing (HLB) is a destructive disease of citrus caused by phloem-limited bacteria, namely 'Candidatus Liberibacter asiaticus' (Las), 'Candidatus Liberibacter africanus', and 'Candidatus Liberibacter americanus'. Although there are no known HLB-resistant citrus species, studies have reported Poncirus trifoliata as being more tolerant. Assuming that callose deposition in the phloem of infected plants can inhibit translocation of photosynthetic products and cause starch accumulation, we compared callose deposition in petioles and starch accumulation in infected leaves of three genotypes (Citrus sinensis, C. sunki, and $P$. trifoliata) and 15 hybrids $(C$. sunki $\times P$. trifoliata $)$. Compared with the mock-inoculated plants, higher bacterial counts and greater accumulation

of callose and starch were found in C. sinensis, C. sunki, and 10 of the hybrid plants. Lower titer and fewer metabolic changes due to Las infection were observed in P. trifoliata and in two Las-positive hybrids while three hybrids were Las-negative. Callose accumulation was linked to and correlated with genes involved in phloem functionality and starch accumulation was linked to up-regulation of genes involved in starch biosynthesis and repression of those related to starch breakdown. Lower expression of genes involved in phloem functionality in resistant and tolerant plants can partially explain the absence of distinct disease symptoms associated with starch accumulation that are usually observed in HLBsusceptible genotypes.
\end{abstract}

Huanglongbing (HLB) is a devastating disease of citrus and is one of the greatest problems in most citrus producing regions (Bové 2006). The disease was discovered in São Paulo State, Brazil, in 2004 (Coletta-Filho et al. 2004) and in Florida, United States, in 2005 (Halbert 2005). HLB leads to premature plant decline and excessive yield loss, which result in heavy economic loss (Bassanezi et al. 2013). HLB is caused by the infection of the Gram-negative bacterium Liberibacter, a noncultivated alpha-proteobacterium that lives in the phloem of plants (Tsai and Liu 2000). There are three HLB-associated Liberibacter species, namely 'Candidatus Liberibacter asiaticus' (Las), 'Candidatus Liberibacter americanus', and 'Candidatus Liberibacter africanus' (Bové 2006). Among these, Las is most widespread in citrus producing areas. HLB is naturally transmitted by psyllids (Diaphorina citri) and can be experimentally transmitted by grafting or by Cuscuta spp. (dodder). The first visible foliar symptoms in citrus orchards are blotchy mottle, yellow shoots, and sectored leaf drop (Johnson et al. 2014). However, due to a latent period between infection and the appearance of symptoms in infected trees and possible confusion with other disorders, HLB diagnosis cannot only rely on symptoms alone, and methods such as real-time quantitative PCR (qPCR) are currently used for HLB diagnosis.

The disease damages fruit yield as it interferes with characteristics such as total soluble solids, acidity, and total soluble solids/ acidity ratio (Dagulo et al. 2010). The appearance of blotchy mottling with green islands on leaves of the infected trees is the result of physiological reactions that occur in response to infection (Albrecht et al. 2014). The symptoms of Las infection indicate that phloem function, metabolism, hormonal stimuli, and biosynthesis of secondary metabolites are all adversely affected (Mafra et al. 2013), and it has been shown that numerous pathways, including

Corresponding author: M. Cristofani-Yaly;

E-mail address: mariangela@centrodecitricultura.br

(c) 2017 The American Phytopathological Society those involved in photosynthesis, sucrose and starch metabolism, source-to-sink transportation, and hormone synthesis and signaling are altered postinfection (Martinelli et al. 2012).

Cytological changes such as callose deposition at the sieve plates, sieve-element necrosis, and starch accumulation have been documented in several studies (Aritua et al. 2013; Fan et al. 2010, 2012; Kim et al. 2009; Koh et al. 2012). Etxeberria et al. (2009) investigated the distribution of starch throughout HLB-affected plants using microscopy and found that starch accumulation was higher in the all aerial tissues of HLB-positive plants compared with HLB-negative plants. Contrarily, starch was depleted in root tissues of HLB-positive plants while substantial starch deposits were observed in HLBnegative plants.

Plant growth relies on the controlled and efficient distribution of certain sugars across plant organs by the phloem, and source-to-sink transport of sugar is one of the major functions of phloem-based transport (Lemoine et al. 2013). Las infection seems to disturb phloem function and, histologically, it is accompanied by the deposition of callose and followed by the collapse and necrosis of sieve elements (Brodersen et al. 2014; Koh et al. 2012). Secondary effects of the disease such as accumulation of starch in leaves and a decrease in the carbohydrate content of sink tissues such as roots can easily be accounted for by the inhibition of phloem transport (Johnson et al. 2014). Chlorosis is generally believed to be caused by the accumulation of carbohydrates in leaves as a result of the inhibited photosynthesis.

As stated above, the development of HLB symptoms is considered to be the consequence of a number of cellular, physiological, and molecular changes and may also be associated with host defense response. Available reports on these changes describe the molecular basis of the host response to Las infection; and gene expression studies have demonstrated that, in general, bacterial infections cause expression changes in several genes involved in plant defense, protein, carbohydrate, sugar and energy metabolism, phytohormones, transport, and environmental stress response mechanisms among others (Scheideler et al. 2002; Schenk et al. 2000; Tao et al. 2003). Several studies have used transcriptome analysis and reported 
changes in global gene expression profiles (Albrecht and Bowman 2008, 2012; Kim et al. 2009; Rawat et al. 2015; Xu et al. 2015; Zheng and Zhao 2013). Recently, next-generation sequencing technologies have also been applied to characterize Las-infections (Martinelli et al. 2015) and to examine how the pathogen regulates source-to-sink transport (Martinelli et al. 2013). These studies have revealed that several thousand genes are either induced or repressed by HLB bacterial infection.

Currently, there is no known cure for the infection, and management is both difficult and costly. Strategies for HLB control include planting pathogen-free nursery stock, vector control by applying insecticides, and removing the inoculum by destroying infected trees (Grafton-Cardwell et al. 2013). Nonetheless, the best option would be to cultivate citrus genotypes that are unaffected or resistant to infection (Gottwald 2010). Unfortunately, all commercial Citrus cultivars are susceptible to Las infection (Bové 2006), and among the most susceptible ones are: mandarins ( $C$. reticulata Blanco), tangelos (hybrids of $C$. reticulata and $C$. paradisi), and sweet oranges $(C$. sinensis L.). However, the preliminary analysis of different Citrus cultivars and varieties has indicated that there are differences in host response to HLB. Further, some cultivars used as rootstocks are known to be tolerant to Las infection (Stover et al. 2010; Albrecht and Bowman 2012).

HLB tolerance/resistance has been frequently reported in $P$. trifoliata, and studies show lower bacterial titer and less severe symptoms (Folimonova et al. 2009). In greenhouse experiments, after graft inoculation with infected buds, no well-defined disease symptoms were observed in $P$. trifoliata trees and seedlings (Albrecht and Bowman 2011). A recent study has demonstrated that a trifoliata hybrid US-897 (C. reticulata $\times$ P. trifoliata) displays tolerance to HLB (Albrecht and Bowman 2011). Transcriptional analysis of this hybrid has uncovered a number of genes potentially associated with tolerance to Las (Albrecht and Bowman 2012). According to the authors, the observed tolerance of Poncirus and its hybrids to Las is probably due to the presence of certain compounds within the phloem that restrict proliferation or movement of Liberibacter. Several accessions of $P$. trifoliata have also been found to be resistant to colonization by psyllids (Richardson and Hall 2013; Westbrook et al. 2011). According to Hall et al. (2015), reduced oviposition on $P$. trifoliata could be a consequence of the presence of factors that are normally missing during oviposition, or factors that deter oviposition, reduce egg hatch, or result in poor survival of nymphs.

Our group is conducting a broad breeding program to improve citrus species using controlled crosses (Boava et al. 2011; Schinor et al. 2013). Several studies on HLB have been conducted with an $\mathrm{F}_{1}$ population of hybrids (also known as citrandarins) obtained by interspecies crosses between $C$. sunki and $P$. trifoliata. Using graft inoculation in a greenhouse, we observed differences in the rate of multiplication of Las both in the parents and in the progeny; the infection rate was higher in $C$. sunki compared with $P$. trifoliata and wide variation was documented among the hybrids (Marengo 2009). More recently, these hybrids have been evaluated after being established in a field with a high incidence of HLB (Boava et al. 2015). These plants were divided in two experimental areas (area A and area B) that were located approximately $10 \mathrm{~m}$ apart. Area A consisted of Pera sweet orange (C. sinensis (L.) Osb.) grafted onto 56 different citrandarins rootstocks (three replicates) while area B consisted of 275 citrandarins as scions grafted onto the Rangpur lime (C. limonia Osb.) rootstock (three replicates). Bacterial presence in the leaves and roots was detected using real-time qPCR, and the incidence of Las-infected plants was $92 \%$ in area A and $14 \%$ in area B, implying that the hybrids of trifoliata are at least more tolerant to HLB than the sweet oranges.

Understanding the molecular basis of susceptibility or tolerance among the different genotypes and the identification of the host factors responsible for disease progression will greatly assist the development of new control strategies.
Therefore, the purpose of the present work was to examine changes in plant physiology and associated them with expression patterns of genes involved in sugar and carbohydrate metabolism, starch breakdown, and phloem functionality. As well as investigating whether there are significant differences in physiological changes and gene expression patterns among a sample of hybrids of the citrandarins population previously studied under field conditions by Boava et al. (2015). Thus, if these differences are found, the citrandarins population may be used for inheritance studies and genetic mapping related to resistance to Las infection.

For this purpose, we selected 15 hybrids (Boava et al. 2015), the parental $C$. sunki and P. trifoliata, and the $C$. sinensis, as a control plant, for study. We reported greater differences in callose deposition in leaf petioles and starch accumulation in the leaves of the infected plants compared with mock-inoculated controls among the studied genotypes. Since genes are differentially expressed in the tolerant and susceptible genotypes, it was possible to identify promising gene transcripts involved in disease tolerance.

\section{MATERIALS AND METHODS}

Vegetal material. Sweet orange Pera (Citrus sinensis L. Osb.), Sunki mandarin (C. sunki), trifoliata orange (Poncirus trifoliata 'Rubidoux'), and 15 hybrids obtained from crosses between $C$. sunki and $P$. trifoliata were propagated using buds that were grafted onto rootstocks of a 6-month-old Rangpur lime (C. limonia Osb.). After 6 months, plants were graft-inoculated with budwood from HLB-infected plants, which were grafted on the opposite side of the plant's primary stem. Budwoods for infection were obtained from HLB-symptomatic Pera sweet orange plants. Infected budwoods were left on the plants, but shoots from these budwoods were eliminated upon sprouting. All plants were maintained in a greenhouse with an average temperature of $25^{\circ} \mathrm{C}$. The experiment used a completely randomized design consisting of three biological replicates for each inoculated (Las-infected budwood) and mockinoculated (healthy budwood) genotype. Leaves and petioles were harvested at 18 months after inoculation for starch quantification and callose detection. Some leaves were flash-frozen in liquid nitrogen and stored at $-80^{\circ} \mathrm{C}$ for DNA and RNA isolation.

Leaf sampling and DNA isolation. Leaves of similar age and position and at the same developmental stage, i.e., young leaves ( 2 months old) and mature leaves (10 months old), were collected from four sides of the plant. Petioles from eight leaves were combined and 200-mg subsamples were lysed by grinding with two beads ( $3 \mathrm{~mm}$ diameter) in 2-ml microtubes at $30 \mathrm{~Hz}$ for $120 \mathrm{~s}$ in a TissueLyser II (Qiagen). DNA extraction was carried out using the CTAB method as described earlier (Murray and Thompson 1980). Precipitated DNA was dissolved in $50 \mu \mathrm{l}$ of DNase-free water and its quality was checked by electrophoresis in $1.2 \%$ agarose gels. DNA concentration was determined using a NanoDrop 8000 spectrophotometer (Thermo Scientific) and adjusted to $100 \mathrm{ng} / \mu \mathrm{l}$.

Las quantification. The degree of Las infection was quantified by qPCR using $16 \mathrm{~S}$ ribosomal DNA (rDNA) primers and the FAM/ Iowa Black FQ label probe (IDT Inc., Coralville, IA) for amplification as described by $\mathrm{Li}$ et al. (2006). The amplified fragment was electrophoresed on a $2 \%$ low melting agarose gel. The expected target band was cut out in situ and purified using the Qiaquick gel extraction kit (Qiagen) according to the manufacturer's instructions. The purified DNA was ligated in the pGEM-T vector (Promega) and the recombinant plasmid was used to transform competent Escherichia coli DH5 $\alpha$. The recombinant plasmid was extracted with Pure Yield Plasmid Miniprep System (Promega) following the manufacturer's instructions, sequenced, and aligned using the BLASTn program. Concentration of the original plasmid standard solution was quantified on a NanoDrop 8000 spectrophotometer (Thermo Scientific). It was diluted in 10 -fold serial dilutions until target DNA concentration became 
$10^{-10}$-fold diluted to generate a standard curve in order to calculate bacterial titer according to Boava et al. (2015).

Callose detection. Callose detection was carried out on petioles of leaves of similar age, position, and developmental stage (10-month-old mature leaves) obtained from four sides of the plant. The central part of the petiole was cut into $2 \mathrm{~cm}$ sections and petiole sections from both inoculated and mock-inoculated plants of all genotypes were immediately transferred to the FAA solution $(50 \mathrm{ml}$ of $37 \%$ formaldehyde, $50 \mathrm{ml}$ glacial acetic acid and $900 \mathrm{ml}$ of $70 \%$ ethanol). After $72 \mathrm{~h}$ incubation in FAA solution, the samples were maintained in $70 \%$ ethanol and callose was detected by aniline blue staining as described in Ruzin (1999). Briefly, petioles were cut into $50 \mu \mathrm{m}$ thick transversal sections on a sliding microtome (Leica, SM2010R), stained with $0.01 \%$ aniline blue $(0.1 \mathrm{M}$ phosphate buffer, pH 9.0) for $10 \mathrm{~min}$, rinsed with deionized water, and trimmed to remove ground tissues. The embedded samples were examined on an Olympus BX61 fluorescent microscope using 355 to $375 \mathrm{~nm}$ excitation filter, 400-nm dichromatic mirror, and 435 to $490 \mathrm{~nm}$ emission filter. Five leaf samples from each plant and 10 sections from each sample were examined; representative images are shown in Figure 1. The presence of callose was quantified by counting the number of fluorescent spots in the phloem of each sample.

Starch quantification. Leaves were dried in an oven at $60^{\circ} \mathrm{C}$ for $72 \mathrm{~h}$. The dried material was ground using two beads (3-mmdiameter) in 2-ml microtubes at $30 \mathrm{~Hz}$ for $120 \mathrm{~s}$ on a TissueLyser II (Qiagen) and subjected to starch quantitation. Starch content was estimated by enzymatic analysis using $10 \mathrm{mg}$ of dried leaves according to Amaral et al. (2007). Absorbance was measured at $490 \mathrm{~nm}$ in an ELISA plate with Glucose (Sigma Aldrich) as standard.

RNA extraction and cDNA synthesis. Total RNA was isolated using the MasterPure Plant RNA Purification Kit (Epicentre Biotechnologies, Madison, WI) according to the manufacturer's instructions and genomic DNA was eliminated using DNase. RNA quality was verified by ethidium bromide staining after separation on a formaldehyde agarose gel. RNA concentration was determined using a NanoDrop ND-8000 spectrophotometer (Thermo Scientific). cDNA was synthesized from $1.0 \mu \mathrm{g}$ of total RNA using Superscript III (200 U/ $\mu \mathrm{l})$ (Invitrogen) and an oligo (dT) primer (dT $12-18$, Invitrogen) according to the manufacturer's instructions. cDNA was treated with RNase $\mathrm{H}(1 \mathrm{U})$ for $20 \mathrm{~min}$ at $37^{\circ} \mathrm{C}$ to remove contaminant RNA.

Analysis of gene expression by qPCR. The synthesized cDNA was used for evaluating gene expression of nine genes involved in sugar and carbohydrate metabolism, starch breakdown and phloem functionality using qPCR with GAPDH as the reference gene (Table 1). Two genes involved in sugar and carbohydrate metabolism (UDP-glucose and beta-glucosidase) were selected based on a previous RNA-seq study by our group that focused on the differential expression of transcripts between Las-infected and control plants of $P$. trifoliata, $C$. sunki, and their hybrids. Starch breakdown genes were selected based on results presented by Fan et al. (2010) who reported that these genes are involved in the leaf transitory starch degradation pathway. Genes involved in phloem functionality were selected based on a transcriptome study of susceptible citrus genotypes by Mafra et al. (2013).

Primers were designed using PerlPrimer software (freeware, http://perlprimer.sourceforge.net/). Amplicon lengths ranged between 90 to $120 \mathrm{bp}$ with an annealing temperature of $60^{\circ} \mathrm{C}$. Primers specificity was checked in silico against the NCBI database (https://www.ncbi. nlm.nih.gov/) using the Primer-BLAST tool, primers tested by PCR, and their specificity checked by melt curve analysis. Amplicons were sequenced on an ABI 3730 sequencer (Applied Biosystems, Foster City, CA) using DyeTerminator chemistry to confirm their identity. PCR primer efficiency ( $E$ value) of each primer pair was also determined using standard curves generated by fivefold serial dilutions of the cDNA synthesized from each treatment in triplicate and calculated using the equation $E=\left(10^{-1 / \text { slope }}-1\right)$ (Fan et al. 2012).
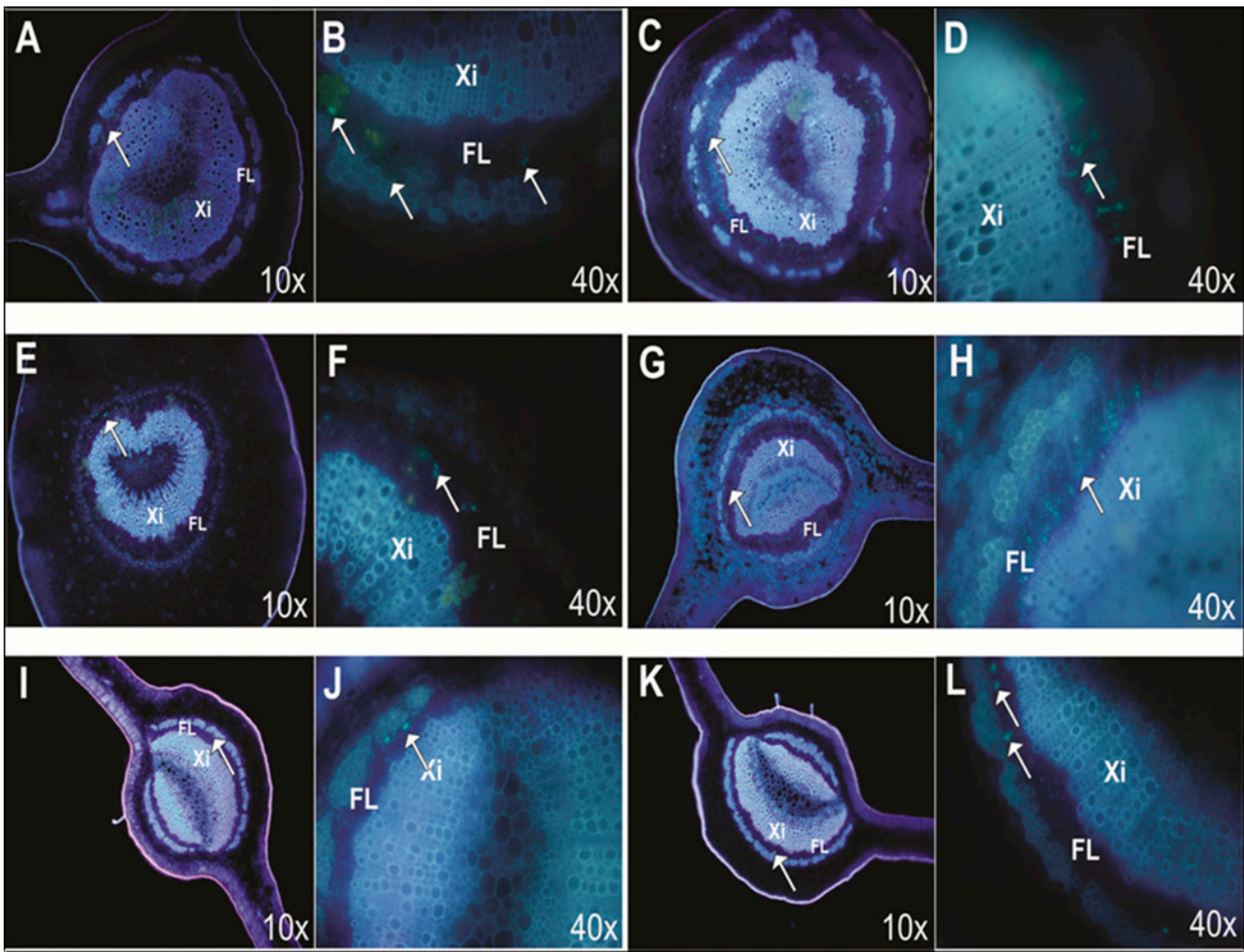

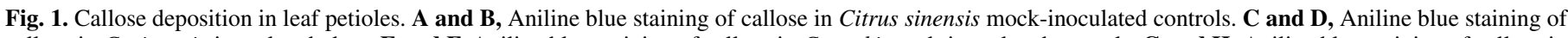

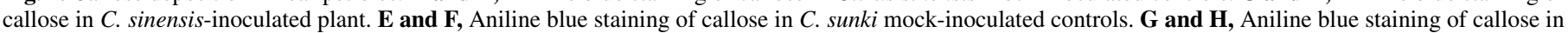

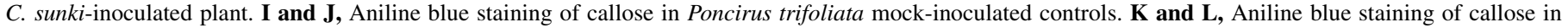
P. trifoliata-inoculated plant. FL, phloem; Xi, xylem. 
RT-qPCR was performed using the GoTaq qPCR Master Mix (Promega). The reaction mixture consisted of $3.0 \mu \mathrm{l}$ of cDNA and $120 \mathrm{nM}$ of each gene-specific primer in a final volume of $14 \mu \mathrm{l}$. Amplification was carried on three replicates of each sample with appropriate negative controls on an ABI PRISM 7500 SDS (Applied Biosystems) thermal cycler with the following conditions: $50^{\circ} \mathrm{C}$ for $2 \mathrm{~min}, 95^{\circ} \mathrm{C}$ for $10 \mathrm{~min}, 40$ cycles of $95^{\circ} \mathrm{C}$ for $15 \mathrm{~s}$, and $60^{\circ} \mathrm{C}$ for $1 \mathrm{~min}$. Expression levels were quantified based on the number of amplification cycles needed to reach a common fixed threshold (cycle threshold [Ct]) in the exponential phase of the PCR. For relative quantification, the $2^{-\Delta \Delta C t}$ method was applied (Livak and Schmittgen 2001). Gene expression was calculated as fold change in Las-infected samples compared with the respective uninoculated plant with GAPDH as reference gene.

Statistical analysis. Standard deviations were used to calculate significant differences. Pearson's correlation coefficient value and the test of the value being different from zero were estimated with functions "cor" and "cor.test" in R Stats package (https://www. r-project.org/). All studied genotypes were tested for an association between gene transcript levels and Las titer, callose accumulation, and starch content variation using correlation analysis.

\section{RESULTS}

Las quantification. C. sinensis, C. sunki, P. trifoliate, and 15 hybrids obtained from crosses between $C$. sunki and $P$. trifoliata were inoculated with budwood from HLB-infected plants. Las presence was detected by qPCR and the results are given in Figure 2.

We were able to efficiently graft transmit the pathogen in almost all the tested genotypes using infected budwood, but were unable to detect the bacteria in any replicate of three hybrids (H31, H90, and H118). All the other genotypes were Las-positive in all replicates and there was substantial variation among the hybrids with respect to their response to Las infection.

All replicates of sweet oranges, Sunki mandarins, and trifoliata were infected after 18 months; however, sweet oranges and Sunki mandarins displayed higher infection levels (higher Las titer). An examination of the responses of 15 hybrids to inoculation with Las revealed a wide range of Las titer among the different hybrids, and the most sensitive hybrids that had higher Las titers were H19, H24, H117, H119, and H150.

Callose detection. Petioles from the inoculated and the mockinoculated plants were collected for callose quantification by aniline blue staining. Callose was quantified by counting the number of fluorescent spots of callose in the phloem from each sample (Fig. 3).

Compared with mock-inoculated plants, callose accumulation in the petioles of the inoculated sweet oranges and Sunki mandarins was, respectively, 169 and 160 times more abundant in Las-positive phloem cells compared with Las-negative phloem cells, whereas the same in trifoliata was only two times more abundant.

In the Las-negative hybrids (H31, H90, and H118), no differences in the number of fluorescent callose spots between Las-positive and Las-negative phloem were observed. In the 12 Las-positive hybrids, 10 showed significant differences $(P \leq 0.01)$ in callose accumulation that ranged between 9- to 100-fold, while two Las-positive hybrids (H66 and H102) showed no significant differences in callose accumulation between Las-positive and Las-negative phloem.

Starch quantification. Starch content was estimated by enzymatic analysis to investigate changes in its abundance during infection in leaves of all plants used in this study (Fig. 4).

The starch content of Las-positive leaves was significantly higher compared with Las-negative leaves. The highest starch content was found in infected sweet orange and Sunki mandarin leaves and was fourfold and fivefold higher in Las-positive C. sinensis and C. sunki, respectively, compared with Las-negative. No such starch accumulation was observed in the leaves of infected $P$. trifoliata and in the three Las-negative hybrids (H31, H90, and H118). Of the 12 Laspositive hybrids, nine showed significant differences (ranging from twofold to fourfold) in starch content between infected and noninfected plants, while in contrast, the three Las-positive hybrids (H35, H66, and H102) did not show significant differences in starch accumulation.

TABLE 1. Oligonucleotide primers pairs used for qPCR analysis

\begin{tabular}{|c|c|c|c|}
\hline & Description & Forward/reverse & Reference \\
\hline \multirow[t]{2}{*}{$P P 2 B 10$} & Phloem protein 2 & AGATTAGTGTTGCCGCTGGT/ & Mafra et al. (2013) \\
\hline & & GAAGGAAGGGTTTCCAGGTC & \\
\hline$U D P$ & UDP-glucose & CGCTTGGAACACAAAGGAATAAA/ & \\
\hline \multirow[t]{2}{*}{ STARC } & Starch synthase & AACTGGGAGCCCACACTATG/ & Mafra et al. (2013) \\
\hline & & CCGGTTCACAATTCCCTTTA & \\
\hline \multirow[t]{2}{*}{ GWD1 } & Glucan-water dikinase & AGGCTTACAGACCTGCTCCA/ & Fan et al. (2010) \\
\hline & & ТСССАСАТСТССТТСАССТС & \\
\hline \multirow{2}{*}{$D P E 1$} & D-enzyme & TTATCTTCAGTGGCCCGAAC/ & Fan et al. (2010) \\
\hline & & TCCAACTCCAGTTTCCGAAC & \\
\hline \multirow[t]{2}{*}{$D P E 2$} & Transglucosidase & CAAGGCATTTCCCTCATCAT/ & Fan et al. (2010) \\
\hline & & TTTCTTTGGAAACTGGTGCC & \\
\hline \multirow[t]{2}{*}{$M E X 1$} & Maltose exporter & CATGTGGATGCCAGTTTCAC/ & Fan et al. (2010) \\
\hline & & CGTGGGATCAGAAGTCCATT & \\
\hline GLUC & Beta-glucosidase & CGACTGCCCAAATTCACAAA/ & \\
\hline
\end{tabular}

TABLE 2. Pearson correlation coefficients among transcript level and 'Candidatus Liberibacter asiaticus' (Las) quantification, callose accumulation, and starch content in Citrus sinensis, C. sunki, Poncirus trifoliate, and 15 hybrids obtained from crosses between $C$. sunki and P. trifoliata ${ }^{\mathrm{a}}$

\begin{tabular}{lccccccccccc}
\hline & Starch & Callose & $P P 2$ & UDP & STARC & GWD1 & DPE1 & GLUC & BAM3 & DPE2 & MEX1 \\
\hline Las & $0.65^{*}$ & $0.84^{*}$ & $0.74^{*}$ & $0.63^{*}$ & $0.70^{*}$ & 0.31 & 0.45 & 0.43 & 0.38 & $-0.55^{*}$ & $-0.58^{*}$ \\
Starch & & $0.76^{*}$ & $0.83^{*}$ & $0.61^{*}$ & $0.56^{*}$ & 0.48 & 0.10 & 0.14 & $0.51^{*}$ & $-0.75^{*}$ & $-0.2^{*}$ \\
Callose & & & $0.77^{*}$ & $0.58^{*}$ & $0.62^{*}$ & 0.20 & 0.41 & 0.25 & $0.45^{*}$ & $-0.52^{*}$ & $-0.48^{*}$ \\
\hline
\end{tabular}

a $*$ Indicates significance at $P \leq 0.01$. 
Correlation. Each genotype was tested for a correlation between Las titer, callose accumulation and starch content (Table 2), and the correlation coefficients (Fig. 5), revealed that Las titer has a significant positive correlation with the callose accumulation $(R=0.84, P=0.01)$ and starch content $(R=0.65, P=0.01)$, and that callose accumulation and starch content are also significantly positively correlated $(R=0.76, P=0.01)$.

Based on Las quantification, callose detection, and starch quantification, the genotypes were classified into three groups: (i) susceptible: $C$. sinensis, $C$. sunki, and 10 Las-positive hybrids; (ii) resistant: Las-negative hybrids (H31, H90, and H118); and (iii) tolerant: $P$. trifoliata and two Las-positive hybrids (H66 and H102) with negligible callose and starch accumulation. We furthermore investigated expression of nine genes involved in phloem functionality, carbohydrate metabolism, and starch breakdown after Las inoculation of these genotypes.

Gene expression by RT-qPCR. Gene expression changes in all the plants were expressed as fold change compared with the respective mock-inoculated control plants. RT-qPCR was performed to evaluate changes in the expression of nine genes involved in sugar and carbohydrate metabolism, starch breakdown and phloem functionality with citrus GAPDH as the reference gene (Fig. $6)$. PCR efficiencies of the target and reference genes were verified (data not shown) prior to using the comparative Ct method (Livak and Schmittgen 2001) for quantifying changes in gene expression.

Notable changes in transcript levels were observed in Lasinfected leaves. Of the nine genes tested, six showed significant changes in expression between infected and mock-inoculated controls of $C$. sinensis, $C$. sunki, $P$. trifoliata, and some hybrids. Phloem protein 2 (PP2) expression was significantly induced $(P \leq$ $0.01)$ in $C$. sinensis, $C$. sunki, and in 10 of the 12 Las-positive hybrids. In contrast, no significant changes were observed in P. trifoliata, two Las-positive hybrids (H66 and H102), and the three Las-negative hybrids (H31, H90, and H118). Similarly, UDPglucose was also significantly induced $(P \leq 0.01)$ in $C$. sinensis, $C$. sunki, and all 12 Las-positive hybrids but not in P. trifoliata and the three Las-negative hybrids (H31, H90, and H118). The expression level of the starch synthase gene also increased significantly $(P \leq 0.01)$ in response to Las infection in $C$. sinensis, $C$. sunki, and 8 of the 12 Las-positive hybrids, but no significant changes were observed in P. trifoliata, three Las-negative hybrids, and four Las-positive hybrids (H45, H66, H102, and H119). The expression of Glucan-water dikinase, D-enzyme, and $\beta$-glucosidase were not affected by HLB infection in either Las-positive or Lasnegative hybrids. The $\beta$-amylase gene expression was slightly reduced in three Las-positive hybrids (H24, H31, and H66) and two

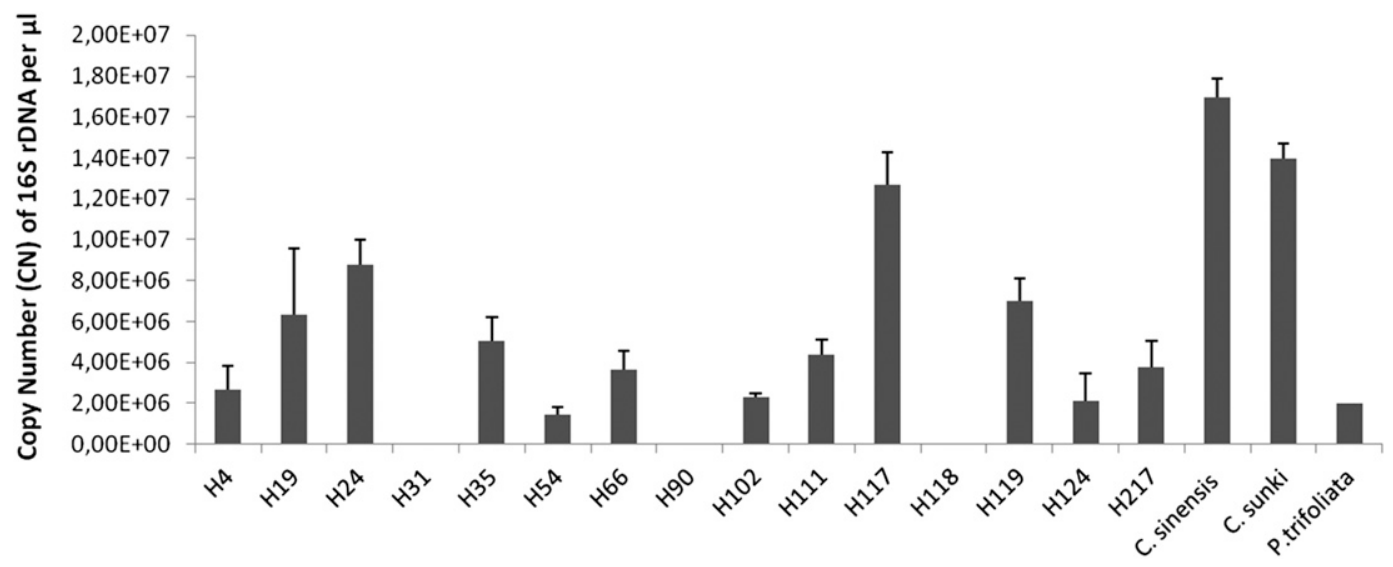

Fig. 2. 'Candidatus Liberibacter asiaticus' quantification performed by qPCR amplifications using sets of $16 \mathrm{~S}$ ribosomal DNA (rDNA) of Citrus sinensis, C. sunki, Poncirus trifoliate, and 15 hybrids obtained from crosses between $C$. sunki and P. trifoliata. Vertical bars represent standard deviations of the means of three replicates.

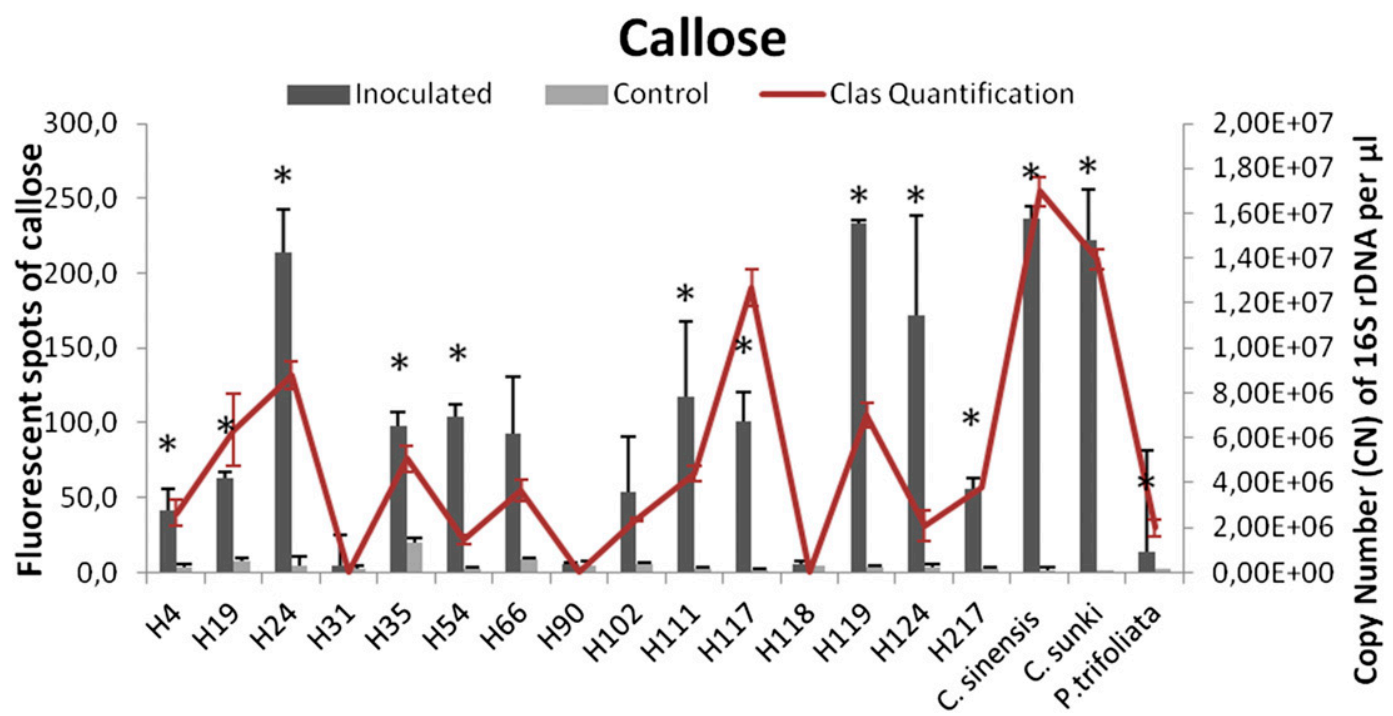

Fig. 3. Callose quantification in leaf petioles of Citrus sinensis, C. sunki, Poncirus trifoliate, and 15 hybrids obtained from crosses between $C$. sunki and P. trifoliata. Callose was detected after aniline blue staining as described in Ruzin (1999). Callose quantification was determined by the number of fluorescent spot of callose in the phloem from each sample. Vertical bars represent standard deviations of the means of three replicates. *, $P \leq 0.01$ by Student's $t$ test. Secondary axis (z) represents 'Candidatus Liberibacter asiaticus' quantification performed by qPCR amplifications using sets of 16S ribosomal DNA. 
Las-negative hybrids (H31 and H90), and no significant changes were observed in $C$. sinensis, $C$. sunki, or $P$. trifoliata. Transglucosidase and maltose exporter gene expression was significantly down-regulated in $C$. sinensis, $C$. sunki, and in 10 Las-positive hybrids compared with mock-inoculated controls.

Gene expression correlation. The expression levels of the three genes were found to have a significant positive correlation $(P \leq$ 0.01 ) with Las titer, with transcript variations in PP2, UDP-glucose and starch synthase accounting for 74,63 , and $70 \%$ of the variation in Las titer, respectively. Two genes (transglucosidase and maltose exporter) were negatively correlated $(P \leq 0.01)$ with Las titer and accounted for 55 and $58 \%$ of the variation, respectively.

PP2, UDP-glucose and starch synthase were also significantly correlated with starch content and callose accumulation and explained 83,61 , and $56 \%$ of the variation in starch content, and 77,58 , and $62 \%$ of the variation in callose accumulation, respectively. Transglucosidase and maltose exporter levels were also negatively correlated $(P \leq 0.01)$ with starch content and callose accumulation and accounted for 75 and $42 \%$ of the variation in starch content and 52 and $48 \%$ of the variation in callose accumulation, respectively.

\section{DISCUSSION}

Although resistant cultivars are rare, some genotypes infected by Las show low Las titer and develop negligible HLB symptoms (Folimonova et al. 2009). P. trifoliata and some of its hybrids are an example of such a variety in which distinct disease symptoms are often not apparent.

It is very difficult to judge which plant has a higher titer of Las because Las is unevenly distributed in citrus (Teixeira et al. 2008). Therefore, we used qPCR to verify variation in infection rates and the reaction to infection among the genotypes using graftinoculated plants with infected budwood. All replicates of $C$. sinensis, $C$. sunki, $P$. trifoliata, and 15 hybrids were evaluated 18 months after inoculation. $C$. sinensis and $C$. sunki had higher Las titers compared with $P$. trifoliata. Furthermore, microbial titer values varied widely among the 15 hybrids, with five hybrids having high titers and three hybrids showing no infection. These results are consistent with previous observations in greenhouse experiments (Marengo 2009) and in naturally infected trees where P. trifoliata and their hybrids were found to be most tolerant or resistant to Las infection (Boava et al. 2015; Folimonova et al. 2009). This result also implies that the genetic composition of the host may influence Las multiplication. This inference is further supported by the wide variation in rate of infection among the hybrids. While efficiency of graft transmission could also explain the difference in infection rates; however, Las presence could be detected in all source budwoods (including Las-negative genotypes) used for inoculation when they were harvested at 18 months (data not shown), implying efficient infection.

A previous study with these hybrids in field conditions (Boava et al. 2015) also demonstrated differences in the rate of multiplication of Las in both parents and progeny. However, in that study, it was difficult to clearly define if the resistance or tolerance of $P$. trifoliata and its hybrids to Las was related to bacteria or to the psyllids, as the observed differences may have been due to several factors, such as the level of attraction between plants and the psyllids, systemic movement of Las and its subsequent proliferation, and differences in tolerance levels to psyllids and/or Las. So we decided to study part of these hybrids under greenhouse conditions and correlate the differences in Las infection within the genotypes with a well-described metabolic disorder in Las-infected citrus tissue that is the deposition of callose in phloem elements which is followed by the hyper-accumulation of starch in the aerial parts and its disappearance from the roots (Etxeberria et al. 2009).

Associated with responses to biotic and abiotic stresses the callose accumulation is considered an important plant defense mechanism. The callose is a polymer $\beta$-1,3-glucan units that accumulate in the phloem sieved plates, the pollen grain wall, and pollen tubes in response to a pathogen attack or some type of wounding in order to reinforce the cell wall or reduce the spread of infection (Nakashima et al. 2003; Xie and Hong 2011). When accumulate in the callose sieved plates, together with the phloem protein (PP2), reduces the phloem functionality by reducing the transport of carbohydrates source of organs (mainly leaves) to the drain organs (roots, flowers, and fruits). Under stress conditions, phloem becomes nonfunctional and there is considerable accumulation of carbohydrates in leaves (Xie and Hong 2011).

Therefore, also in citrus, the callose appears to play an important role in the responses of defense to biotic stresses. The question that arises is what is its role in the different pathosystems of citrus? As a general mechanism of cell wall strengthening or of sieve plates or plasmodesmatas blocking, callose is a very important defense

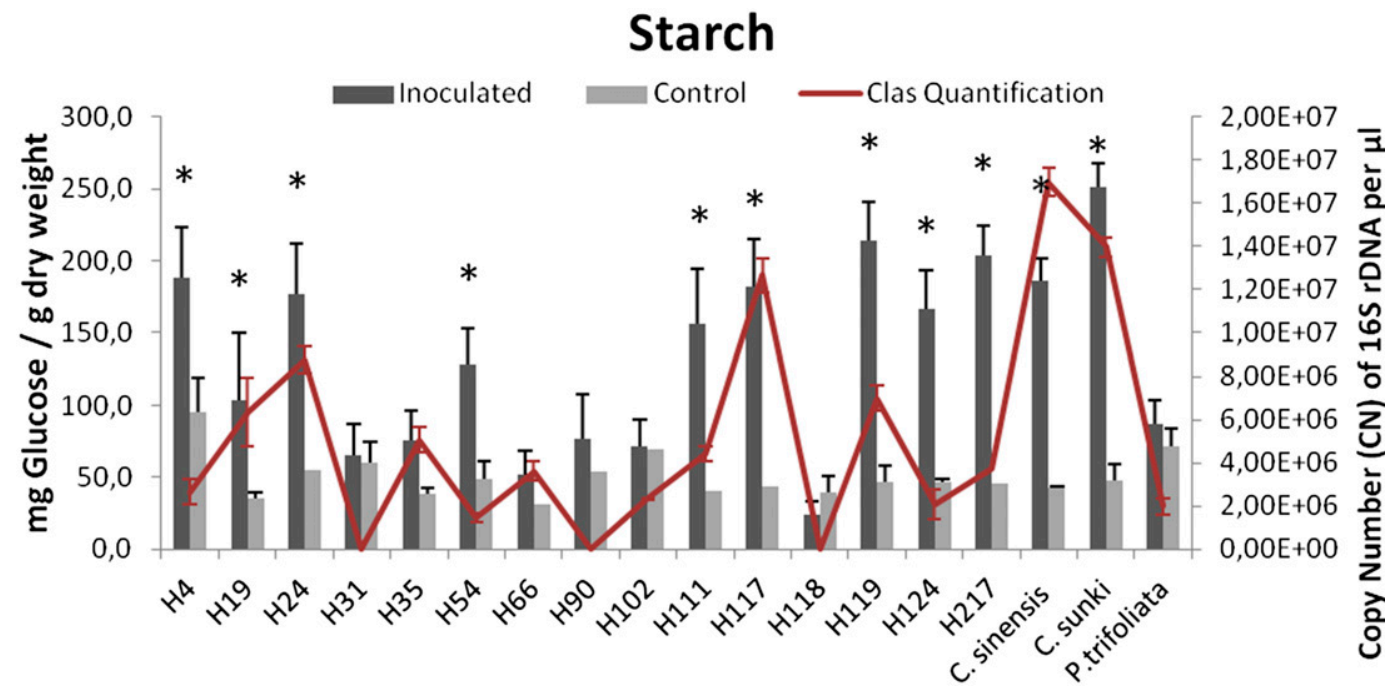

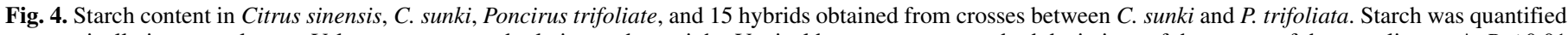

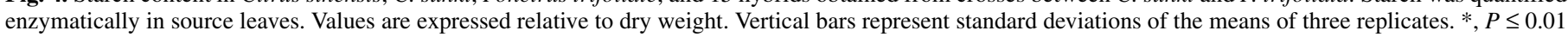

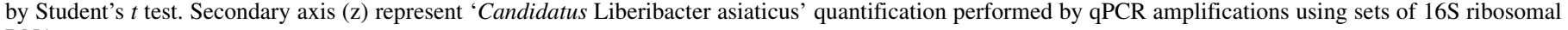
DNA. 
mechanism for invasive tissue pathogens such as Xanthomonas citri subsp. citri or fungi or oomycetes. For intracellular pathogens inoculated by vectors such as Liberibacter, phytoplasma, or Spiroplasma, the callose accumulation mechanism could be seen as a hypersensitivity reaction of tissue, whose main consequence would be to isolate spatially the pathogen and reduce their colonizing ability via the phloem. To trigger this response, the plant reduces or prevents the proper functioning of phloem, with the consequent reduction in the transport of assimilates to the drain organs and accumulation in organs supply, especially leaves. On the other hand, the deficiency or absence of photoassimilate transport to sink-organs, such as fruits and roots, could explain the irregular growth (deformed fruits) or reduction of growth or functionality of the root system.

The preferential sequestration of photoassimilates, mainly as starch in leaves, represents carbohydrate imbalance that may culminate in plant death. Thus, we compared the deposition of callose in petioles and the accumulation of starch in leaves between inoculated and mock-inoculated plants. The results revealed that Las titers exhibited significant positive correlation with the callose accumulation and starch content, and that callose accumulation and starch content were also significantly positively correlated.

Comparison between the inoculated and the mock-inoculated plants, higher Las titers, and greater callose and starch accumulation were found in $C$. sinensis, $C$. sunki, and in 10 of the 15 hybrids at inoculated condition. The accumulation of callose in the phloem and starch in the leaf parenchyma suggests that Las infection substantially altered both phloem function and sugar mobilization from photosynthetic tissues in the affected genotypes. These observations are in agreement with previous studies (Aritua et al. 2013; Etxeberria et al. 2009; Fan et al. 2010, 2012; Kim et al. 2009; Koh et al. 2012), which also reported starch accumulation in the leaves due to Las infection. Notably, the authors of these reports hypothesized that phloem blockage is responsible for starch accumulation, and Koh et al. (2012) stated that, in HLB-infected trees, the low titers of Las, combined with evidence of transport inhibition, suggested that the observed symptoms are indeed related to phloem blockage induced by the bacterial infection rather than by direct destruction of phloem. Consequently, photosynthesis is inhibited because photosynthetic products accumulate in chloroplasts and reduce the supply of sugars from the source (leaves) to the sink (roots).

On the other hand, and apart from the Las-negative hybrids (H31, H90, and H118), only a few metabolic changes and much lower Las titers were noted in $P$. trifoliata. Interestingly, two Las-positive hybrids (H66 and H102) also displayed no significant differences in callose and starch accumulation when compared with Las-negative plants. Fan et al. (2012) suggested that this partial augmentation in phloem transport activities in Las-infected plants may be due to the formation of new functional phloem tissues as there is a concurrent upregulation of cell wall biosynthesis genes. Furthermore, according to Stover et al. (2010), because hybrids of Poncirus may vary in their tolerance to Las, it is possible that they segregate for tolerance/ resistance to HLB presumably derived from their $P$. trifoliata parent.

The findings reported here corroborate the hypothesis suggested by Stover et al. (2010) and enabled classification of the genotypes into three groups: (i) susceptible: $C$. sinensis, $C$. sunki, and 10 Las-positive hybrids; (ii) resistant: Las-negative hybrids (H31, H90, and H118); and (iii) tolerant: P. trifoliata and two Laspositive hybrids (H66 and H102) with negligible callose and starch accumulation.

We then hypothesized that genes that are differentially expressed between these three groups will provide promising candidates that confer HLB tolerance. Thus, we investigated gene expression after Las infection using nine genes involved in phloem functionality, sugar and carbohydrate metabolism and starch breakdown and found that phloem protein 2 (PP2) was strongly induced in the susceptible genotype while its expression was not altered in the resistant or tolerant hybrids. PP2, besides being involved in the differentiation of vascular tissue, has several functions including sieve cell differentiation, host defense responses such as plugging of sieve pores to prevent insect and pathogen colonization, enlargement of the size exclusion limits of mesophyll plasmodesmata, and the movement of large signal molecules such as RNA and proteins (Dinant et al. 2003).

UDP-glucose, which is necessary for cell wall and glycoprotein biosynthesis, was another gene that was induced in the susceptible group but not in most of the tolerant and resistant genotypes. UDPglucose is used by callose synthase as glucose donor for the growing polymer chain (Santi et al. 2013). UDP-glucose may form a complex with callose synthase I and is localized at the cell plate of cytokinetic cells (Hong et al. 2001). Thus, the ready availability of UDP-glucose, probably caused by the enhanced cleavage activity of sucrose synthase, can explain both starch and callose accumulation often observed in infected phloem tissue (Santi et al. 2013). Interestingly, even though this gene was induced in two hybrids from the tolerant group, starch accumulation was not
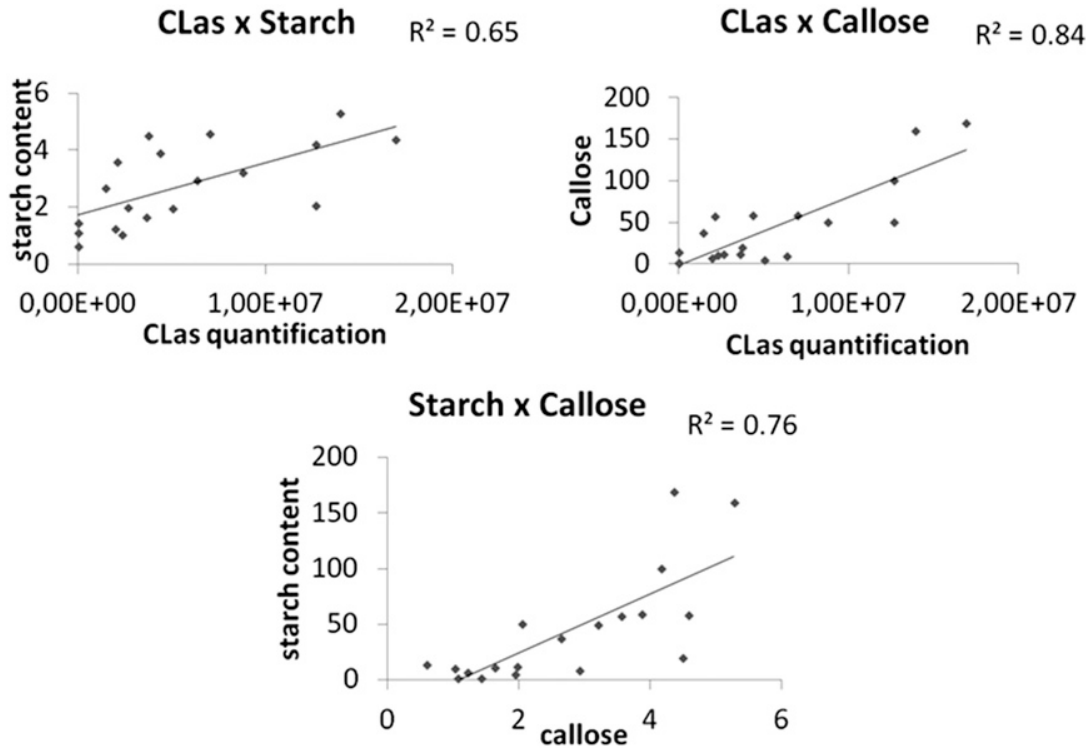

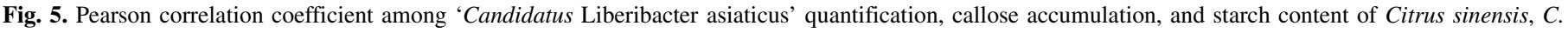
sunki, Poncirus trifoliate, and 15 hybrids obtained from crosses between C. sunki and P. trifoliate. 
observed in these genotypes. Importantly, this finding suggests that the magnitude of change in gene expression in tolerant genotypes is insufficient to cause significant phloem blockage and the subsequent accumulation of photosynthetic products in the chloroplasts as it is well documented that susceptibility or resistance is determined not just by the presence or absence of genes, but also by the magnitude of their expression (Ryals et al. 1996).
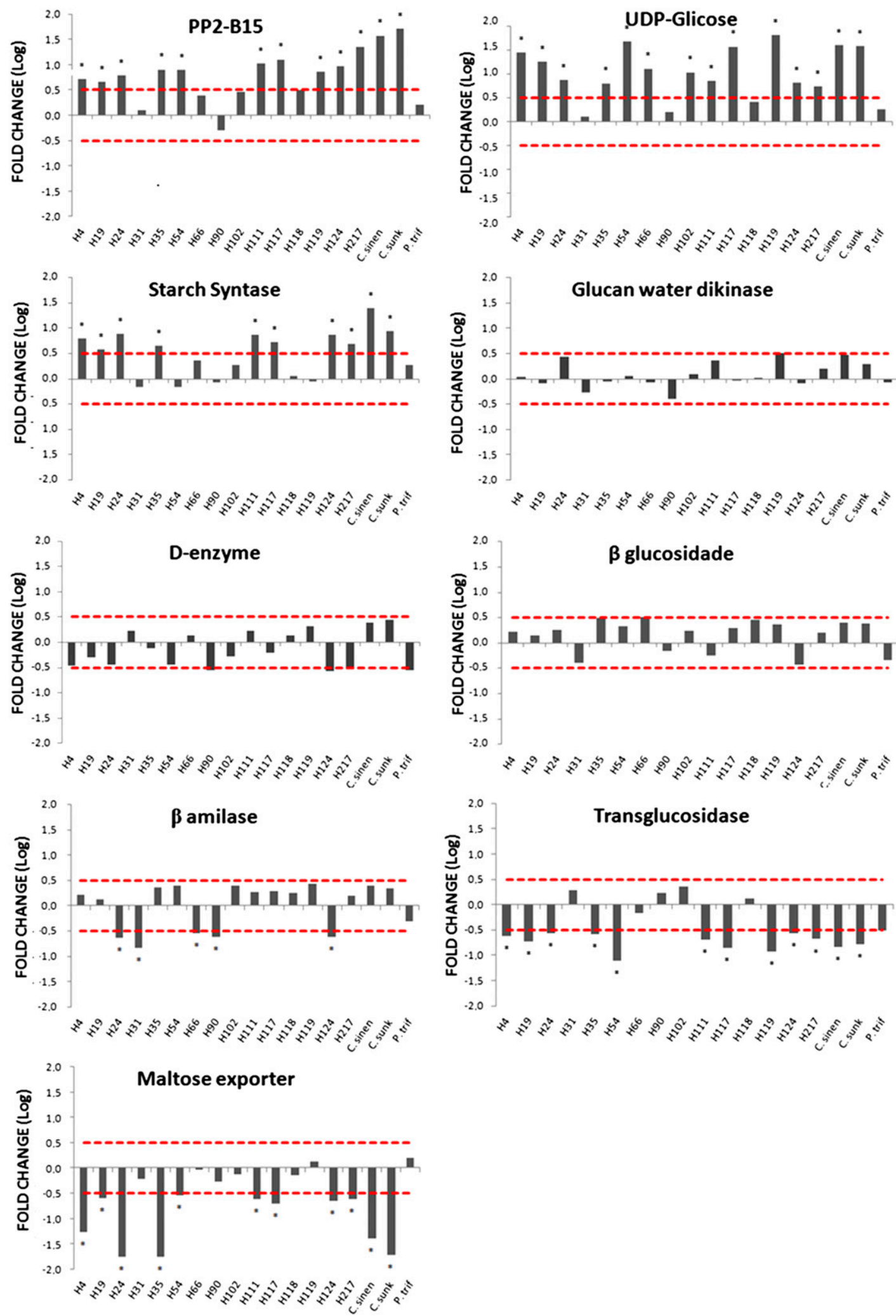

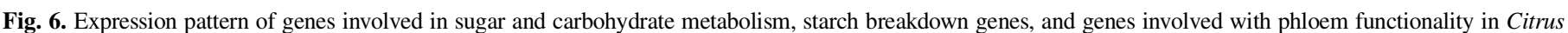

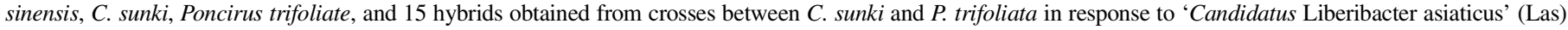

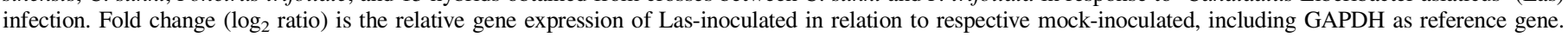

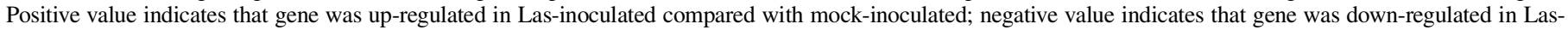
inoculated compared with mock-inoculated. The ratio is the mean of three replicates. * indicates that transcripts ratio was significant $(P \leq 0.01)$. 
Another characteristic symptom of HLB infection, as evidenced by our results, is the accumulation of starch in the chloroplasts of the leaves. Starch is a natural product of photosynthetic $\mathrm{CO}_{2}$ fixation in green tissues and sucrose conversion in storage cells. Starch biosynthesis is controlled by four major enzymes namely: ADPase, starch synthase, granule-bound starch synthase, and starch debranching enzyme (Nwugo et al. 2013). We found a significant increase in starch synthase gene expression in infected $C$. sinensis, $C$. sunki, and in 8 of the 10 Las-positive hybrids from the susceptible group suggesting that this excessive starch accumulation was partly due to the up-regulation of starch synthesis in the susceptible genotypes. This result corroborates the observations of Kim et al. (2009), who reported an upregulation of three genes necessary for starch biosynthesis which probably lead to starch formation from accumulated sucrose. Importantly and in contrast, we observed that this gene was not induced in the resistant or tolerant genotypes.

In addition to phloem blockage, other factors, including limited starch breakdown due to down-regulation of starch-degrading genes also contribute to the starch accumulation during Las infection (Aritua et al. 2013).

Substantial progress has been made in understanding transitory starch breakdown. It is now believed that transitory starch is broken down to glucose and maltose in the chloroplast by the debranching enzymes, D-enzyme, $\beta$-amylase, glucan-water dikinase, and phosphoglucan water dikinase (Baunsgaard et al. 2005; Kötting et al. 2005; Lu and Sharkey 2006; Scheidig et al. 2002). Our results showed that the expression of glucan-water dikinase and D-enzyme were not affected by Las infection in the susceptible group, and that rather, $\beta$-amylase expression was slightly reduced in two Las-positive hybrids from the susceptible group, two resistant genotypes, and in one from the tolerant group. According to Sivak and Preiss (1998), the breakdown of starch involves $\beta$-amylase, at least initially, as it is the only enzyme known to attack starch granules. The cooperative actions of other degrading enzymes, including starch phosphorylase, $\alpha$-amylase, $\beta$-glucosidase, and the debranching enzyme, result in the dissolution of stored starch through the production of oligosaccharides that finally leads to the production of glucose, maltose, or glucose-1-phosphate (Irving et al. 1997).

Several studies indicate that maltose is the major product of starch hydrolysis; it increases when starch breakdown is induced and is exported from the chloroplast at night (Lu and Sharkey 2006; Weise et al. 2004). When transitory starch is most probably degraded by the action of several hydrolyzing enzymes the major carbohydrates released are maltose and glucose (Stitt and Zeeman 2012). Starch-derived maltose enters the cytosol via the maltose exporter and is further metabolized by transglucosidase which transfers one of its glucosyl residues to cytosolic heteroglycans and releases the second as free glucose (Fettke et al. 2006). In this study, transglucosidase and maltose exporter were down-regulated in the leaves of all HLB-infected genotypes of the susceptible group compared with mock-inoculated controls. Fan et al. (2010) also reported similar down-regulation of enzymes involved in starch metabolism such as transglucosidase and the maltose exporter. They further showed that the decrease in transglucosidase and maltose exporter expression levels was accompanied by a reduction in maltose levels. This reduction in maltose levels in Las-infected leaves probably indicates that starch breakdown is repressed, although enhanced starch biosynthesis cannot be excluded (Albrecht and Bowman 2008).

In conclusion, we could detect variation in Las abundance among the genotypes studied which can be interpreted as evidence of resistance or tolerance to Las in P. trifoliata and some of its hybrids. The accumulation of both callose in the phloem and starch in the leaf parenchyma suggest that phloem function and sugar mobilization from photosynthetic tissues were affected by Las infection. The expression of certain indicator genes revealed clear differences among the genotypes depending on plant phenology, as in the petioles, callose accumulation was associated to genes involved in phloem functionality, while in leaves, starch accumulation was linked to an up-regulation of genes involved in starch biosynthesis and the repression of genes involved in starch breakdown. Low callose accumulation and the accompanying changes in the expression levels of genes involved phloem functionality in the resistant and tolerant groups may explain why these genotypes, like other trifoliata species and its hybrids, do not display distinct disease symptoms associated with the starch accumulation in HLB-susceptible genotypes.

The results of the present work provide strong support that the population of citrandarins can be used for further studies of inheritance and genetic mapping related to resistance to Las infection.

These promising genotypes and other Poncirus hybrids are being planted and will be used to identify genes associated with Las resistance/tolerance. Once identified, such genes can potentially be used to develop HLB-resistant or HLB-tolerant transgenics and/or be used in marker-assisted selection of conventional hybrids derived from $P$. trifoliata in order to develop strategies to remedy the negative effect of HLB in citrus.

\section{ACKNOWLEDGMENTS}

This study was conducted with the financial support of Fundação de Amparo a Pesquisa do Estado de São Paulo (FAPESP) (Processes 2007/ 08435-5 and 2011/18605-0) and Instituto Nacional de Ciência e Tecnologia (INCT) de Genômica para Melhoramento de Citros (Process 573848/20084) and a Postdoctoral fellowship to Leonardo Pires Boava (process 2012/ 01917-2) from Fundação de Amparo a Pesquisa do Estado de São Paulo (FAPESP). M. Cristofani-Yaly and M. A. Machado are recipients of research fellowships from CNPq.

\section{LITERATURE CITED}

Albrecht, U., and Bowman, K. D. 2008. Gene expression in Citrus sinensis (L.) Osbeck following infection with the bacterial pathogen 'Candidatus Liberibacter asiaticus' causing Huanglongbing in Florida. Plant Sci. 175: 291-306.

Albrecht, U., and Bowman, K. D. 2011. Tolerance of the trifoliata citrus hybrid US-897 (Citrus reticulata Blanco $\times$ Poncirus trifoliata L. Raf.) to Huanglongbing. HortScience 46:16-22.

Albrecht, U., and Bowman, K. D. 2012. Transcriptional response of susceptible and tolerant citrus to infection with 'Candidatus Liberibacter asiaticus'. Plant Sci. 185-186:118-130.

Albrecht, U., Hall, D. G., and Bowman, D. K. 2014. Transmission efficiency of 'Candidatus Liberibacter asiaticus' and progression of huanglongbing disease in graft- and psyllid-inoculated citrus. HortScience 49:367-377.

Amaral, L. I. V., Gaspar, M., Costa, P. M. F., Aidar, M. P. M., and Buckeridge, M. S. 2007. Novo método enzimático rápido e sensível de extração e dosagem de amido em materiais vegetais. Hoehnea 34:425-431.

Aritua, V., Achor, D., Gmitter, F. G., Albrigo, G., and Wang, N. 2013. Transcriptional and microscopic analyses of citrus stem and root responses to 'Candidatus Liberibacter asiaticus' infection. PLoS ONE 8:e73742.

Bassanezi, R. B., Montesino, L. H., Gimenes-Fernandes, N., Yamamoto, P. T., Gottwald, T. R., Amorim, L., and Bergamin Filho, A. 2013. Efficacy of area-wide inoculum reduction and vector control on temporal progress of huanglongbing in young sweet orange plantings. Plant Dis. 97:789-796.

Baunsgaard, L., Lutken, H., Mikkelsen, R., Glaring, M. A., Pham, T. T., and Blennow, A. 2005. A novel isoform of glucan, water dikinase phosphorylates pre-phosphorylated $\alpha$-glucans and is involved in starch degradation in Arabidopsis. Plant J. 41:595-605.

Boava, L. P., Cristofani-Yaly, M., Mafra, V. S., Kubo, K., Kishi, L. T., Takita, M. A., Ribeiro-Alves, M., and Machado, M. A. 2011. Global gene expression of Poncirus trifoliata, Citrus sunki and their hybrids under infection of Phytophthora parasitica. BMC Genomics 12:39.

Boava, L. P., Sagawa, C. H., Cristofani-Yaly, M., and Machado, M. A. 2015. Incidence of 'Candidatus Liberibacter asiaticus'-infected plants among citrandarins as rootstock and scion under field conditions. Phytopathology 105:518-524.

Bové, J. M. 2006. Huanglongbing: A destructive, newly-emerging, century-old disease of citrus. J. Plant Pathol. 88:7-37.

Brodersen, C., Narciso, C., Reed, M., and Etxeberria, E. 2014. Phloem production in Huanglongbing-affected citrus trees. HortScience 49:59-64.

Coletta-Filho, H. D., Targon, M. L. P. N., Takita, M. A., De Negri, J. D., Pompeu, J. J., and Machado, M. A. 2004. First report of the causal agent of huanglongbing ('Candidatus Liberibacter asiaticus') in Brazil. Plant Dis. $88: 1382$. 
Dagulo, L., Danyluk, M. D., Spann, T. M., Valim, F. M., Goodrich-Schneider, R., Sims, C., and Rouseff, R. 2010. Chemical characterization of orange juice from trees infected with Citrus greening (Huanglongbing). J. Food Sci. 75:C199-C207.

Dinant, S., Clark, A. M., Zhu, Y., Vilaine, F., Palauqui, J. C., and Kusiak, C. 2003. Diversity of the superfamily of phloem lectins (phloem protein 2) in angiosperms. Plant Physiol. 131:114-128.

Etxeberria, E., Gonzalez, P., Achor, D., and Albrigo, G. 2009. Anatomical distribution of abnormally high levels of starch in HLB-affected Valencia orange trees. Physiol. Mol. Plant Pathol. 74:76-83.

Fan, J., Chen, C., Brlansky, R. H., Gmitter, F. G., Jr., and Li, Z. G. 2010. Changes in carbohydrate metabolism in Citrus sinensis infected with 'Candidatus Liberibacter asiaticus'. Plant Pathol. 59:1037-1043.

Fan, J., Chen, C., Yu, Q., Khalaf, A., Achor, D. S., and Brlansky, R. H. 2012. Comparative transcriptional and anatomical analyses of tolerant rough lemon and susceptible sweet orange in response to 'Candidatus Liberibacter asiaticus' infection. Mol. Plant-Microbe Interact. 25:1396-1407.

Fettke, J., Chia, T., Eckermann, N., Smith, A. M., and Steup, M. 2006. A transglucosidase necessary for starch degradation and maltose metabolism in leaves acts on cytosolic heteroglycans (SHG). Plant J. 46:668-684.

Folimonova, S. Y., Robertson, C. J., Garnsey, S. M., Gowda, S., and Dawson, W. O. 2009. Examination of the responses of different genotypes of citrus to huanglongbing (citrus greening) under different conditions. Phytopathology 99:1346-1354.

Gottwald, T. R. 2010. Current epidemiological understanding of citrus huanglongbing. Annu. Rev. Phytopathol. 48:119-139.

Grafton-Cardwell, E. E., Stelinski, L. L., and Stansly, P. A. 2013. Biology and management of Asian citrus psyllid, vector of the Huanglongbing pathogens. Annu. Rev. Entomol. 58:413-432.

Halbert, S. E. 2005. The discovery of huanglongbing in Florida. Page H-3 in: Proc. 2nd International Citrus Canker and Huanglongbing Research Workshop. Florida Citrus Mutual, Orlando, FL.

Hall, D. G., George, J., and Lapointe, S. L. 2015. Further investigations on colonization of Poncirus trifoliata by the Asian citrus psyllid. Crop Prot. 72: $112-118$.

Hong, Z., Zhang, Z., Olson, J. M., and Verma, D. P. S. 2001. A novel UDP-glucose transferase is part of the callose synthase complex and interacts with phragmoplastin at the forming cell plate. Plant Cell 13: 769-779.

Irving, D. E., Hurst, P. L., and Ragg, J. S. 1997. Changes in carbohydrates and carbohydrate metabolizing enzymes during the development, maturation, and ripening of buttercup squash (Cucurbita maxima D. 'Delica'). J. Am. Soc. Hortic. Sci. 122:310-314.

Johnson, E. G., Wu, J., Bright, D. B., and Graham, J. H. 2014. Association of 'Candidatus Liberibacter asiaticus' root infection, but not phloem plugging with root loss on huanglongbing-affected trees prior to appearance of foliar symptoms. Plant Pathol. 63:290-298.

Kim, J. S., Sagaram, U. S., Burns, J. K., Li, J. L., and Wang, N. 2009. Response of sweet orange (Citrus sinensis) to 'Candidatus Liberibacter asiaticus' infection: Microscopy and microarray analyses. Phytopathology 99:50-57.

Koh, E. J., Zhou, L., Williams, D. S., Park, J., Ding, N., Duan, Y. P., and Kang, B. H. 2012. Callose deposition in the phloem plasmodesmata and inhibition of phloem transport in citrus leaves infected with 'Candidatus Liberibacter asiaticus'. Protoplasma 249:687-697.

Kötting, O., Pusch, K., Tiessen, A., Geigenberger, P., Steup, M., and Ritte, G. 2005. Identification of a novel enzyme required for starch metabolism in Arabidopsis leaves. The phosphoglucan, water dikinase. Plant Physiol. 137: 242-252.

Lemoine, R., La Camera, S., and Atanassova, R. 2013. Source to sink transport and regulation by environmental factors. Front. Plant Sci. 4:272.

Li, W., Hartung, J. S., and Levy, L. 2006. Quantitative real-time PCR for detection and identification of Candidatus Liberibacter species associated with citrus huanglongbing. J. Microbiol. Methods 66:104-115.

Livak, K. J., and Schmittgen, T. D. 2001. Analysis of relative gene expression data using real-time quantitative PCR and the $2^{-\Delta \Delta C T}$ method. Methods 25: 402-408.

Lu, Y., and Sharkey, T. D. 2006. The importance of maltose in transitory starch breakdown. Plant Cell Environ. 29:353-366.

Mafra, V., Martins, P. K., Francisco, C. S., Ribeiro-Alves, M., Freitas-Astúa, J., and Machado, M. A. 2013. 'Candidatus Liberibacter americanus' induces significant reprogramming of the transcriptome of the susceptible citrus genotype. BMC Genomics 14:247.

Marengo, S. 2009. Mapeamento genético de tangerina sunki e Poncirus trifoliata para resistência ao huanglongbing (greening) dos citros. Dissertação de mestrado, Agricultura Tropical e Subtropical, Area de Concentração em Genética, Melhoramento Vegetal e Biotecnologia. IAC.
Martinelli, F., Ibanez, A. M., Reagan, R. L., Davino, S., and Dandekar, A. M. 2015. Stress responses in citrus peel: Comparative analysis of host responses to Huanglongbing disease and puffing disorder. Sci. Hortic. (Amsterdam) 192:409-420.

Martinelli, F., Reagan, R. L., Uratsu, S. L., Phu, M. L., Albrecht, U., and Zhao, W. 2013. Gene regulatory networks elucidating huanglongbing disease mechanisms. PLoS ONE 8:e74256.

Martinelli, F., Uratsu, S. L., Albrecht, U., Reagan, R. L., Phu, M. L., and Britton, M. 2012. Transcriptome profiling of citrus fruit response to huanglongbing disease. PLoS ONE 7:e38039.

Murray, M., and Thompson, W. F. 1980. Rapid isolation of high molecularweight plant DNA. Nucleic Acids Res. 8:4321-4325.

Nakashima, J., Laosinchai, W., Cui, X., and Brown, R. M. 2003. New insight into the mechanism of cellulose and callose biosynthesis: Protease may regulate callose biosynthesis upon wounding. Cellulose 10:369-389.

Nwugo, C. C., Lin, H., Duan, Y., and Civerolo, E. L. 2013. The effect of 'Candidatus Liberibacter asiaticus' infection on the proteomic profiles and nutritional status of pre-symptomatic and symptomatic grapefruit (Citrus paradisi) plants. BMC Plant Biol. 13:59.

Rawat, N., Kiran, S. P., Du, D., Gmitter, F. G., Jr., and Deng, Z. 2015. Comprehensive meta-analysis, co-expression, and miRNA nested network analysis identifies gene candidates in citrus against Huanglongbing disease. BMC Plant Biol. 15:184.

Richardson, M. L., and Hall, D. G. 2013. Resistance of Poncirus and Citrus $\times$ Poncirus germplasm to the Asian citrus psyllid. Crop Sci. 53:183-188.

Ruzin, S. 1999. Plant Microtechnique and Microscopy. Oxford University Press, New York.

Ryals, J. A., Neuenschwander, U. H., Willits, M. G., Molina, A., Steiner, H. Y., and Hunt, M. D. 1996. Systemic acquired resistance. Plant Cell 8:1809-1819.

Santi, S., Grisan, S., Pierasco, A., Marco, F., and Musetti, R. 2013. Laser microdissection of grapevine leaf phloem infected by stolbur reveals sitespecific gene responses associated to sucrose transport and metabolism. Plant Cell Environ. 36:343-355.

Scheideler, M., Schlaich, N. L., Fellenberg, K., Beissbarth, T., Hauser, N. C., Vingron, M., Slusarenko, A. J., and Hoheisel, J. D. 2002. Monitoring the switch from housekeeping to pathogen defense metabolism in Arabidopsis thaliana using cDNA arrays. J. Biol. Chem. 277:10555-10561.

Scheidig, A., Frohlich, A., Schulze, S., Lloyd, J. R., and Kossmann, J. 2002. Downregulation of a chloroplast-targeted $\beta$-amylase leads to a starch-excess phenotype in leaves. Plant J. 30:581-591.

Schenk, P. M., Kazan, K., Wilson, I., Anderson, J. P., Richmond, T., and Somerville, S. C. 2000. Coordinated plant defense responses in Arabidopsis revealed by microarray analysis. Proc. Natl. Acad. Sci. 97:11655-60.

Schinor, E. H., Cristofani-yaly, M., Batianel, M., and Machado, M. A. 2013. Sunki mandarin vs. Poncirus trifoliata hybrids as rootstocks for Pera sweet orange. J. Agric. Sci. 5:190.

Sivak, M., and Preiss, J. 1998. Starch: Basic science and biotechnology. Adv. Food Nutr. Res. 41:1-131.

Stitt, M., and Zeeman, S. C. 2012. Starch turnover: Pathways, regulation and role in growth. Curr. Opin. Plant Biol. 15:282-292.

Stover, E., Shatters, R., Jr., McCollum, G., Hall, D. G., and Duan, Y. P. 2010. Evaluation of Candidatus Liberibacter asiaticus titer in field-infected trifoliata cultivars: Preliminary evidence for HLB resistance. Proc. Fla. State Hortic. Soc. 123:115-117.

Tao, Y., Xie, Z., Chen, W., Glazebrook, J., Chang, H. S., Han, B., Zhu, T., Zou, G., and Katagiri, F. 2003. Quantitative nature of Arabidopsis responses during compatible and incompatible interactions with the bacterial pathogen Pseudomonas syringae. Plant Cell 15:317-330.

Teixeira, D. C., Saillard, C., Couture, C., Martins, E. C., and Wulff, N. A. 2008. Distribution and quantification of 'Candidatus Liberibacter americanus', agent of huanglongbing disease of citrus in Sao Paulo State, Brasil, in leaves of an affected sweet orange tree as determined by PCR. Mol. Cell. Probes 22:139-150

Tsai, J. H., and Liu, Y. H. 2000. Biology of Diaphorina citri (Homoptera: Psyllidae) on four host plants. J. Econ. Entomol. 93:1721-1725.

Weise, S. E., Weber, A. P. M., and Sharkey, T. D. 2004. Maltose is the major form of carbon exported from the chloroplast at night. Planta 218:474-482.

Westbrook, C. J., Hall, D. G., Stover, E. W., Duan, Y. P., and Lee, R. F. 2011. Susceptibility of Citrus and Citrus-related germplasm to Diaphorina citri (Hemiptera: Psyllidae). HortScience 46:997-1005.

Xie, B., and Hong, Z. 2011. Unplugging the callose plug from sieve pores. Plant Signal. Behav. 6:491-493.

Xu, M., Li, Y., Zheng, Z., Dai, Z., Tao, Y., and Deng, X. 2015. Transcriptional analyses of mandarins seriously infected by 'Candidatus Liberibacter asiaticus'. PLoS ONE 10:e133652.

Zheng, Z. L., and Zhao, Y. 2013. Transcriptome comparison and gene coexpression network analysis provide a systems view of citrus response to 'Candidatus Liberibacter asiaticus' infection. BMC Genomics 14:27. 